\title{
Inhibition of Prostaglandin Biosynthesis by Corticosteroids
}

\author{
MALCOLM W. GREAVES, WENDY MCDONALD-GIBSON
}

British Medical fournal, 1972, 2, 83-84

\section{Summary}

Since prostaglandins have been consistently recovered from a wide range of inflammatory reactions, including cutaneous inflammation, we have studied the effect of the anti-inflammatory corticosteroids hydrocortisone and fluocinolone on in-vitro biosynthesis of prostaglandins by skin. Skin homogenates synthesized prostaglandins $\mathbf{E}_{2}$ and $F_{2} \alpha$ in the presence of an excess of arachidonic acid substrate. Inhibition of biosynthesis of both these prostaglandins by corticosteroids was demonstrated. Since several members of the prostaglandin group of agents can reproduce all the cardinal features of inflammation and are found in a wide range of inflammatory reactions it is concluded that at least part of the anti-inflammatory properties of corticosteroids is due to inhibition of prostaglandin biosynthesis.

\section{Introduction}

Prostaglandins are highly vasoactive (Crunkhorn and Willis, 1971; S $\varnothing$ ndergaard and Greaves, 1971) and have been recovered from several types of inflammatory reactions in man (Ängaård et al., 1970; Greaves and Søndergaard, 1970, Greaves et al., 1971) and in laboratory animals (Di Rosa et al., 1971; Anderson et al., 1971; Ängaård and Jonsson, 1971). We have also shown that prostaglandins are the most consistently recovered vasoactive substances in inflammatory reactions in the skin such as eczema and erythema due to exposure to ultraviolet light (Greaves et al., 1971; Greaves and Sondergaard, 1970). Prostaglandin biosynthesis by skin in vitro was first demonstrated by one of us two years ago (Jessup et al., 1970). We have therefore studied the effect of anti-inflammatory corticosteroids on prostaglandin biosynthesis by skin in vitro.

\section{Methods}

Shaved abdominal skin of freshly killed female albino rats (weight $200 \mathrm{~g}$ approximately) was excised and the subcutaneous fat trimmed off. The skin was weighed and cut into small fragments with scissors before immersion in phosphate buffer (pH 7.4) containing hydroquinone $(0.275 \mathrm{mM})$ and glutathione $(0.325 \mathrm{mM})$ (Foss et al., 1971). After homogenization with a Polytron tissue homogenizer bovine serum albumin was added (final concentration $5 \mathrm{mg} / \mathrm{ml}$ ). The homogenate was then incubated aerobically with an excess of arachidonic acid containing tritium-labelled arachidonic acid tracer (New England Nuclear Inc.) in a shaking water-bath at $37^{\circ} \mathrm{C}$. The final concentration of arachidonic acid was $12.5 \mu \mathrm{g} / \mathrm{ml}$ and the reaction volume $2 \mathrm{ml}$ in all experiments. The reaction was terminated after 40 minutes by adding $10 \mathrm{ml}$ of ice-cold ethanol. After four hours the supernatant was recovered and the residue washed with ice-cold ethanol. The washings and corresponding supernatants were combined and deep-frozen before acidic lipid extraction with petroleum ether and diethyl ether followed by thin-layer chromatography as described by Greaves and McDonald-Gibson

Department of Dermatology, University of Newcastle upon Tyne MALCOLM W. GREAVES, M.D., M.R.C.P., Senior Lecturer

WENDY MCDONALD-GIBSON, Research Assistant
(1972). The prostaglandin $\mathrm{E}_{2}$ and $\mathrm{F}_{2} \alpha$ activity was determined by elution of the zones of the chromatoplate corresponding to simultaneously developed standard prostaglandins $\mathrm{E}_{2}$ and $F_{2} \propto$ followed by determination of radioactivity in these eluates by means of a Packard Tricarb liquid scintillation counter.

That the activity in the eluates recovered from the prostaglandin $E_{2}$ and $F_{2} \alpha$ zones of the chromatoplate contained prostaglandin $\mathrm{E}$ and $\mathrm{F}$ activity respectively was confirmed in a single experiment in which results obtained by determination of radioactivity were compared with results obtained by bioassay of the same eluates using an isolated rat uterus preparation. The results for prostaglandin $\mathrm{E}$ activity determined by the two methods were identical. For prostaglandin $F$ the value determined by bioassay was $78 \%$ of the result determined by estimating radioactivity.

The mean recoveries of prostaglandins $\mathrm{E}_{2}$ and $\mathrm{F}_{2} \alpha$ added to the skin homogenates before incubation both exceeded $90 \%$. Variation in rate of prostaglandins $E_{2}$ and $F_{2} \alpha$ synthesis between different aliquots of the same skin sample under identical conditions was less than $10 \%$.

The effect of corticosteroids on biosynthesis of prostaglandins $F_{2}$ and $F_{2} \alpha$ was studied by adding each drug to the reaction mixture immediately before incubation. All experiments included controls in which arachidonic acid and other reagents were incubated with buffer alone before the addition of skin homogenate, extraction, and thin-layer chromatography.

\section{Results}

Prostaglandin Biosynthesis by Skin.-Synthesis of prostaglandins $E_{2}$ and $F_{2} \propto$ from arachidonic acid by skin homogenates was demonstrated in all experiments. In skin samples from 23 rats the mean total prostaglandin activity synthesized in 40 minutes was $1.39 \pm 0.17$ (S.E.M.) $\mu \mathrm{g} / \mathrm{g}$ wet weight. Of this $65.5 \pm 3.0 \%$ was prostaglandin $\mathrm{E}_{2}$ and $34.5 \pm 3.0 \%$ prostaglandin $\mathrm{F}_{2} \alpha$. By contrast, synthesis of prostaglandin by homogenates in the absence of added arachidonic acid substrate was negligible (prostaglandin E, $20 \mathrm{ng} / \mathrm{g}$; prostaglandin $\mathrm{F}$, nil).

Hydrocortisone and Fluocinolone. - The effects of hydrocortisone $(0.28 \mathrm{mM})$ and fluocinolone $(0.22 \mathrm{mM})$ were studied in experiments on skin from seven rats. Both corticosteroids caused inhibition of prostaglandin synthesis (Fig. 1). Fluocinolone inhibited synthesis of prostaglandin $E_{2}$ and of prostaglandin $F_{2}$

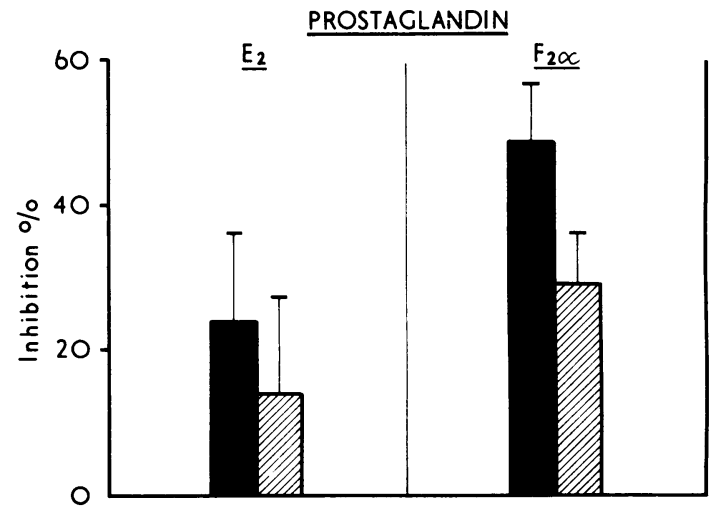

FIG. 1-Inhibition of prostaglandin biosynthesis by corticosteroids (mean and S.E. of mean, 7 experiments). Solid rectangles fluocinolone $(0.22 \mathrm{mM})$. Shaded rectangles hydrocortisone $(0.28 \mathrm{mM})$. Inhibition expressed as difference between prostaglandin synthesis in the presence and absence of corticoence between prostaglandin synthesis in the presence 
and both these effects were statistically significant $(P=0.05$ and 0.02 respectively). Hydrocortisone also inhibited synthesis of both prostaglandins but only the effect on $F_{2} \alpha$ synthesis was statistically significant $(P<0.05)$.

\section{Discussion}

We have confirmed earlier results of one of us (Jessup et al., 1970) and more recently of Van Dorp (1971) that skin converts arachidonic acid substrate enzymically to prostaglandins $E_{2}$ and $F_{2} \alpha$. The present experiments have shown that corticosteroids inhibit prostaglandin biosynthesis. This previously unrecognised mode of action of corticosteroids has important implications in the mechanisms of anti-inflammatory actions of corticosteroids.

Prostaglandins are stored in insignificant amounts in skin (Van Dorp, 1971; Greaves and McDonald-Gibson, unpublished data). By contrast, skin rapidly synthesizes prostaglandins in the presence of excess substrate. This suggests that the reported release of prostaglandins in inflammatory skin conditions is due mainly to stimulation of local biosynthesis rather than to release from pre-existing stores. One such stimulus is probably increased local concentrations of arachidonic acid and other unsaturated fatty acid prostaglandin precursors due to interaction of lysosomal phospholipases and cell membrane phospholipids in inflamed tissues (Vogt et al., 1969; Anderson et al., 1971).

That prostaglandin $E_{2}$ and $F_{2} \alpha$ biosynthesis is inhibited by anti-inflammatory corticosteroids is a finding of great interest and potential importance. Vane (1971) was unable to demonstrate inhibition by hydrocortisone of biosynthesis of prostaglandins by guinea-pig lung tissue although his experiments did show inhibition by aspirin and indomethacin. However, apart from species and tissue differences, he used cell-free supernatants of centrifuged lung homogenates as a source of prostaglandinforming enzymes for his experiments, and it is possible that corticosteroids depend for their inhibitory effect on a cell membrane-bound factor. Until more is known of the detailed mechanism of prostaglandin biosynthesis the precise mechanism of corticosteroid inhibition of prostaglandin biosynthesis is likely to remain speculative.

Work in our own laboratory as well as elsewhere has convincingly shown the ability of several members of the prostaglandin group of agents to mediate the cardinal components of inflammation including vasodilation (Crunkhorn and Willis, 1971; Sondergaard and Greaves, 1971), increased vascular permeability (Horton, 1963; Kaley and Weiner, 1967), leucotaxis (Di Rosa and Willoughby, 1971; Kaley and Weiner, 1971), and pain (Collier, 1971). Prostaglandin $\mathrm{E}_{1}$ is also a potent pyrogen (Feldberg and Saxena, 1971). Using an in-vivo skin perfusion technique we have consistently recovered prostaglandins with these properties from inflamed human skin (Greaves and
Søndergaard, 1970; Greaves et al., 1971), and similar results have been reported both in man and in laboratory animals in skin and other tissues by other workers (Ängaård et al., 1970; Di Rosa et al., 1971; Anderson et al., 1971; Ängaård and Jonsson, 1971). We therefore conclude that the ability of corticosteroids to inhibit local biosynthesis of prostaglandins explains at least part of the anti-inflammatory efficacy of these drugs.

We thank Professor Sam Shuster for his advice. Professor D. Van Dorp and Dr. J. E. Pike kindly gave us standard prostaglandin preparations. This work was supported financially by the Medical Research Council (Grant No. G971/33), the Board of Governors of the Royal Victoria Infirmary, Newcastle upon Tyne, and Fisons Ltd, Pharmaceutical Division.

ADDENDUM: In recent experiments we have extended our results to human skin. Homogenates of human breast skin synthesize prostaglandins $\mathrm{E}_{2}$ and $\mathrm{F}_{2} \alpha$ in the presence of arachidonic acid substrate. Fluocinolone acetonide produced significant inhibition of synthesis of total prostaglandins as well as of prostaglandins $\mathrm{E}_{2}$ and $\mathrm{F}_{2} \alpha$ individually. Hydrocortisone did not cause significant inhibition. These results will be reported in detail elsewhere.

\section{References}

Anderson, A. J., Brocklehurst, W. E., and Willis, A. L. (1971). Pharmacological Research Communications, 3, 13.

Ängaărd, E., Arturson, G., and Jonsson, C. E. (1970). Acta Physiologica Scandinavica, 80, 46A.

Ängaård, E., and Jonsson, E. E. (1971). Acta Physiologica Scandinavica, 81,440 .

Collier, H. O. J. (1971). Nature, 232, 17.

Crunkhorn, P., and Willis, A. L. (1971). British fournal of Pharmacology and Chemotherapy, 41, 49.

Di Rosa, M., Giroud, J. P., and Willoughby, D. A. (1971). Fournal of Pathology, 104, 15.

Di Rosa, M., and Willoughby, D. A. (1971). Fournal of Pharmacy and Pharmacology, 23, 297.

Feldberg, W., and Saxena, P. N. (1971). Fournal of Physiology, 217, 547.

Foss, P., Takeguchi, C., Tai, H., and Sih, C. (1971). Annals of the New York Academy of Sciences, 180, 126.

Greaves, M. W., and McDonald-Gibson, Wendy (1972). Life Sciences, 11, 73.

Greaves, M. W., and Sorndergaard, J. (1970). Fournal of Investigative Dermatology, 54, 365. Greaves, M. W., Sfondergaard, J., and McDonald-Gibson, Wendy (1971).
British Medical fournal, 2, 258.

Horton, E. W. (1963). Nature, 200, 892.

Jessup, S. J., McDonald-Gibson, W. J., Ramwell, P. W., and Shaw, J. E. (1970). Federation Proceedings, 29, 387.

Kaley, G., and Weiner, R. (1967). In Prostaglandin Symposium of the Worcester Foundation for Experimental Biology, ed. P. W. Ramwell and J. E. Shaw, p. 321. New York, Interscience,

Kaley, G., and Weiner, R. (1971). Nature New Biology, 234, 114.

Søndergaard, J., and Greaves, M. W. (1971). British fournal of Dermatology, $84,424$.

Van Dorp, D. (1971). Annals of the New York Academy of Sciences, 180, 181.

Vane, J. R. (1971). Nature New Biology, 231, 232.

Vogt, W., Meyer, U., Kunze, H., Lufft, E., and Babilli, S. (1969). Archiv für Pharmakologie und Experimentelle Pathologie, 262, 124. 